Ophthalmologe 2022 119 (Suppl 2):S151 https://doi.org/10.1007/s00347-021-01472-8 Online publiziert: 2. August 2021

() Der/die Autor(en) 2021

\section{Erratum zu: Stadiengerechte Therapie des Keratokonus}

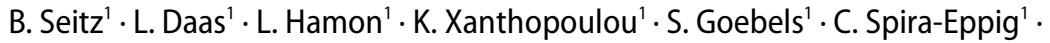 \\ S. Razafimino' $\cdot$ N. Szentmáry ${ }^{2} \cdot$ A. Langenbucher ${ }^{3} \cdot$ E. Flockerzi $^{1}$ \\ 'Klinik für Augenheilkunde und Hochschulambulanz, Universitätsklinikum des Saarlandes UKS, \\ Homburg/Saar, Deutschland \\ ${ }^{2}$ Dr. Rolf M. Schwiete Zentrum für Limbusstammzellforschung und kongenitale Aniridie, Universität des \\ Saarlandes, Homburg/Saar, Deutschland \\ ${ }^{3}$ Institut für Experimentelle Ophthalmologie, Universität des Saarlandes, Homburg/Saar, Deutschland
}

\section{Erratum zu:}

Ophthalmologe 2021

https://doi.org/10.1007/s00347-021-

01410-8

In dem ursprünglichen Artikel wurden die Literaturstelle [21-25] falsch zugeordnet. Die Online-Version sowie das PDF des Beitrags wurden nachträglich korrigiert. Bitte beachten Sie die korrigierten Literaturzitate.

Der vollständige und korrigierte Artikel steht Ihnen auf www.springermedizin.de zur Verfügung. Bitte geben Sie dort den Beitragstitel in die Suche ein.

Die Redaktion

\section{Korrespondenzadresse}

Prof. Dr. med. B. Seitz, ML, FEBO

Klinik für Augenheilkunde und Hochschulambulanz, Universitätsklinikum des Saarlandes UKS

66421 Homburg/Saar, Deutschland berthold.seitz@uks.eu

Open Access. Dieser Artikel wird unter der Creative Commons Namensnennung 4.0 International Lizenz veröffentlicht, welche die Nutzung, Vervielfältigung, Bearbeitung, Verbreitung und Wiedergabe in jeglichem Medium und Format erlaubt, sofern Sie den/die ursprünglichen Autor(en) und die Quelle ordnungsgemäß nennen, einen Link zur Creative Commons Lizenz beifügen und angeben, ob Änderungen vorgenommen wurden.

Die in diesem Artikel enthaltenen Bilder und sonstiges Drittmaterial unterliegen ebenfalls der genannten Creative Commons Lizenz, sofern sich aus der Abbildungslegende nichts anderes ergibt. Sofern das betreffende Material nicht unter der genannten Creative Commons Lizenz steht und die betreffende Handlung nicht nach gesetzlichen Vorschriften erlaubt ist, ist für die oben aufgeführten Weiterverwendungen des Materials die Einwilligung des jeweiligen Rechteinhabers einzuholen.

Weitere Details zur Lizenz entnehmen Sie bitte der Lizenzinformation auf http://creativecommons.org/ licenses/by/4.0/deed.de.
Die Online-Version des Originalartikels ist unter https://doi.org/10.1007/s00347-021-01410-8 zu finden.

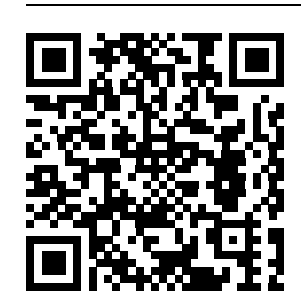

QR-Code scannen \& Beitrag online lesen 